\title{
Estimating the Domestic Demand for Saudi Citrus Using an Almost Ideal Demand Model in Light of Corona Pandemic
}

\author{
Abeer A. Kinawy ${ }^{1,2^{*}}$, Amal S. Alaliol ${ }^{1,3}$, Ibrahim A. Abdelfatah ${ }^{2}$ \\ ${ }^{1}$ Department of Agricultural Business and Consumer Sciences, College of Agricultural and Food Sciences, King Faisal University, \\ Al-Ahsa, KSA \\ ${ }^{2}$ Economic, Department of Agricultural Economics, Faculty of Agriculture, Ain Shams University, Cairo, Egypt \\ ${ }^{3}$ Applied Economics Program, Department of Agricultural Business and Consumer Sciences, King Faisal University, Al-Ahsa, \\ KSA \\ Email: *akinawy@kfu.edu.sa, amal.s@hotmail.com, Dr.ibrahim.ali2030@gmail.com
}

How to cite this paper: Kinawy, A. A., Alaliol, A. S., \& Abdelfatah, I. A. (2022). Estimating the Domestic Demand for Saudi Citrus Using an Almost Ideal Demand Model in Light of Corona Pandemic. Open Journal of Social Sciences, 10, 398-409. https://doi.org/10.4236/jss.2022.102028

Received: January 27, 2022

Accepted: February 25, 2022

Published: February 28, 2022

Copyright $\odot 2022$ by author(s) and Scientific Research Publishing Inc. This work is licensed under the Creative Commons Attribution International License (CC BY 4.0).

http://creativecommons.org/licenses/by/4.0/

(c) (i) Open Access

\begin{abstract}
The world has recently experienced major challenges in all respects in general, and in economic in particular following the Coronavirus pandemic (COVID-19). This has led people to improve their diet by consuming more vitamin-rich food commodities, especially vitamin C, because of its important effect in promoting body immunity and resistance for many diseases and cold diseases. The study relied on secondary data (time series) during the period (2001-2020), collected from various sources. The study estimated the demand function and the different factors affecting demand. The near-optimal demand model in the Saudi market is the models used in the study by analyzing commodity demand equations system according to their variety or sources. The research examined the application of this model in the study of domestic demand for the most important commodities consumed in Saudi Arabia (orange-lemon-tangerines). The results show that the suggested model obtained conditions of the application function, which are addition, homogeneity, symmetry, price, cross demand and expenditure elasticities. It is noted that the own-price demand elasticity was negative, and less than the correct one for lemons, which indicated that it was a necessary commodity. The demand for both oranges and tangerines turned out to be elastic. It also turns out that there is a direct relationship between lemon prices and spending on lemons and tangerines. There is an inverse relationship between the price of both lemons and spending on oranges. It also noted that the indicative of spending elasticity for both oranges and lemons was positive.
\end{abstract}




\section{Keywords}

Semi-Optimal Demand Model, Saudi Arabia, Orange, Lemon, Tangerine

\section{Introduction}

Vitamin $\mathrm{C}$ is one of the most important nutrients you need to stay healthy, helping to improve public health and strengthen the immune system, especially in light of the Coronavirus pandemic. All health and nutrition experts agree that it is not only a vital nutrient, but can also help prevent infection and help relive the disease as it strengthens the immune system, which is crucial in tackling Coronavirus. In order to strengthen the body, it needs certain nutrients, mainly vitamin $\mathrm{C}$. There are many food commodities rich in this vitamin, the most important of which is citrus. The world has recently experienced significant challenges in all respects in general and economic in particular, the impact of the Coronavirus pandemic (COVID 19), which prompted people to improve their diet by consuming more vitamin-rich food commodities, especially vitamin C, because it has important effects in enhancing body immunity and resisting many diseases and colds. One of the most important of these commodities is (oranges, lemons and tangerines), which are important commodities consumed in Saudi society.

\section{Research Problem}

Citrus is one of the most important food commodities for the consumer in Saudi Arabia, where it is consumed from various sources throughout the year, especially in cold weather because of its special importance in fighting viruses and strengthening the immune system. The recent increase in consumption of these commodities reached 273.9, 92.3, 59.5 thousand tons for Orange, Limon, and Tangerine respectively as a average throw the study term.

It's required an estimate of the demand for citrus. In addition to calculating the various elasticity, COVID-19 has led to an increase in the consumption of these commodities, which requires an estimate of the demand for citrus. The research will calculate the various elasticity for citrus to identify the most important effect and different relationships among these important commodities. In addition, the paper will determine the type of demand as well as the importance of citrus commodities to Saudi society.

\section{Research Aim}

Analysis of the elasticity of Saudi domestic demand on the most important citrus commodities consumed in Saudi Arabia. In addition, the paper will estimate the different elasticity (own price, cross-price and expenditure elasticity) and measure the different effect of prices on the required quantities of citrus commodities under the new conditions and the Corona virus pandemic (COVID 19). 


\section{Research Method and Data Sources}

The research in achieving its objectives relied on the use of descriptive and quantitative analysis method using some mathematical and statistical methods, the most important of which is to estimate the almost ideal demand model for citrus consumption. The Almost Ideal Demand System (AIDS) model is one of the models used to study and analyze the equations of demand for the commodity according to its diversity, or its source. The research addressed the application of this model in the study of domestic demand for the most important citrus consumed in Saudi Arabia (oranges, lemons and tangerines). It is expressed by a system of equations following the spending assessments on the consumption of these three fruits items. Then the usage of the non-linear least-squares method to estimate the parameters of the proposed model, conduct all statistical tests of the model features on the one hand, and tests for the limitations of this model on the other hand.

The study relied on secondary data represented in the time series data during the period (2001-2020), which were collected from various sources from the Prices data sources: General Authority for Statistics (Saudi Statistics Authority), Tangerines data source: FAO, the unit of measurement is tons and it has been converted to a thousand tons, Amounts of oranges and lemons are from (https://www.indexmundi.com/) the unit of measure is thousand tons.

\section{Previous Studies}

The research must be based on number of references such as books, letters, research and scientific studies. It is the reference retrieval, the main component, and the point from which the scientific research begins.

(Al-Mahish, El-Radi, \& Mursi, 2021) aimed to estimate the elasticity of demand for tilapia, whitefish and catfish in Egypt. The results showed that the demand for fish in terms of prices in Egypt is inelastic, meaning that the change in prices has little effect on the required amount of fish.

(Amin \& Ali Mohamed, 2020) objective was to estimate the demand functions for orange exports using the almost optimal demand model in the Saudi market, the Russian market and the Ukrainian market during the period (2001-2018). The results of the almost ideal demand model in the Saudi market showed that the price elasticity of demand has an elastic demand, while the spending elasticity is a normal commodity. As for the results of the model in the Russian market, they found that the price elasticity of demand has an elastic demand. As for the spending elasticity, it indicates that it is a normal commodity. As for the results of the model in the Ukrainian market, the price elasticity of demand has an elastic demand, while the expenditure elasticity had been found to be a normal commodity.

(Alnafissa \& Alderiny, 2019) study aims to analyze the Saudi demand for natural honey imported from Yemen, Pakistan, Australia, Argentina, Mexico and Germany during the study period (1991-2017). The results of estimating the ex- 
penditure elasticity of demand using the almost ideal demand model showed that all the own price elasticities were negative and significant except for the own price elasticities associated with the demand for natural honey imported from Pakistan. As for the natural honey imported from Yemen, it has an inelastic demand in terms of price. The results of elasticity across prices showed that there is a relationship between the various imported natural honey products and the estimated values of spending elasticity of demand.

(Al-Duwais, Alderiny, kotb, Ahamed, \& Alropy, 2019) study objective is to estimate the demand function for imports of apples, oranges and bananas in the Kingdom of Saudi Arabia. The equations of demand for the Kingdom's imports of these fruits are homogeneous at zero degree, and it had found that all price elasticities (own and cross elasticities) and expenditure elasticities are compatible with the economic theory.

According to the obtained results of the (Sahinli \& Fidan, 2012) study, it was proved that the price-related change will appear in the demand for food. Expenditures were obtained by product categories and price elasticities, and product categories were joined in the form of bread and cereals; Meat, fish and poultry, milk, dairy products, oil and eggs, vegetables and fruits, various fast food, alcoholic and non-alcoholic drinks.

(Torres, 1996) study aims to analyze the elasticity of demand for citrus imports in the Republic of Germany during the period (1974-1990). The results show that price is one of the main factors that explain the demand for imports, but there are other factors, called "tastes", which plays an important role in evaluating trade flows between exporters and importers.

\section{Results Discussion}

First: (AIDS) Almost Ideal Demand System as follows:

$$
\begin{gathered}
\ln [E(P, U)]=(1-U) \ln [a(P)]+U \ln [b(P)] \\
\ln [a(P)]=\alpha_{0}+\Sigma \alpha_{k} \ln P_{k}+\frac{1}{2} \Sigma_{k} \Sigma_{j} \gamma_{k j} \ln P_{k} \ln P_{j} \\
\ln [b(P)]=\ln [a(P)]+\beta_{0} \Pi_{k} P_{k}^{\beta_{k}}
\end{gathered}
$$

By substituting Equations (2) and (3) into Equation (1), the expenditure function can be formulated as follows:

$$
\ln [E(P, U)]=\alpha_{0}+\Sigma \alpha_{k} \ln P_{k}+\frac{1}{2} \Sigma_{k} \Sigma_{j} \gamma_{k j} \ln P_{k} \ln P_{j}+\beta_{0} U \Pi_{k} P_{k}^{\beta_{k}}
$$

By differentiating $\ln [E(P, U)]$ with respect to its price $\ln P_{i}$, the commodity's share of expenditure $W_{i}$ can be obtained as follows:

$$
\frac{\partial \ln [E(P, U)]}{\partial \ln P}=\frac{P_{i} q_{i}}{E(P, U)}=W_{i}
$$

Thus, Equation (4) can be reformulated as follows: 


$$
\begin{aligned}
& W_{i}=\alpha_{i}+\Sigma_{j} \gamma_{i j} \ln P_{j}+\beta_{i} U \beta_{0} \Pi_{k} P_{k}^{\beta_{k}} \\
& W_{i}=\alpha_{i}+\Sigma_{j} \gamma_{i j} \ln P_{j}+\beta_{i} \ln \left(\frac{E}{P_{\text {index }}}\right)
\end{aligned}
$$

whereas:

$$
\ln \left(P_{\text {index }}\right)=\alpha_{i}+\Sigma_{k} \alpha_{k} \ln P_{k}+\frac{1}{2} \Sigma_{k} \Sigma_{j} \gamma_{k j} \ln P_{k} \ln P_{j}
$$

$P_{\text {index }}$ is considered non-linear and has difficulties in estimation, so it has been replaced by the Stones Price Index as follows:

$$
\ln \left(P_{s p i}\right)=\Sigma_{i} W_{i} \ln P_{i}
$$

Since $W_{i}$ indicates the percentage of expenditure, and it represents the dependent variable in the equations, the use of this index may cause some immediate problems in the model equations, so the lagged periods are used as follows:

$$
\ln \left(P_{s p i}\right)=\Sigma_{i} W_{i}^{\prime} \ln P_{i}
$$

whereas:

$$
W_{i}^{\prime}=\frac{1}{2}\left(W_{i t}+W_{i t-1}\right)
$$

Note that the index $\left(P_{\text {index }}\right)$ can be considered as a linear approximation of the index $\left(P_{s p i}\right)$ in the case of a high multicollinearity between prices, and thus Equation (7) becomes as follows:

$$
W_{i}=\alpha_{i}+\Sigma_{j} \gamma_{i j} \ln P_{j}+\beta_{i} \ln \left(\frac{E}{P_{s p i}}\right)
$$

To apply special conditions of demand to Equation (12), which are represented in:

- Additively $\Sigma_{i} \leftarrow \alpha_{i}=1, \Sigma_{i} \leftarrow \gamma_{i j}=0, \Sigma_{i} \leftarrow \beta_{i}=0$.

- Homogeneity $\Sigma_{j} \leftarrow \gamma_{i j}=0$.

- Symmetry $\gamma_{i j}=\gamma_{j i}$ for $i \neq j$.

The importance of these conditions is that they make the model in line with the theory of demand, where the addition conditions ensure that the condition that the total expenditure $=1$, that is $\left(\sum W_{i}=1\right)$.

The homogeneity conditions guarantee the homogeneity of the demand functions, and the symmetry conditions fulfill the Slutsky condition.

Where, $P_{i}$ indicates price of the item is taken into account. $a$ and $b$ functions in function parameters and prices, m number of crops within each group, $W_{i}$ the commodity's share of expenditure, $P_{i} . q_{i}$, the price and quantity of the items are taken into consideration respectively total expenditure on the commodity in consideration, $P_{\text {index }}$ price Index, $P_{s p i}$ Stones' maximum number.

And Expenditure elasticity are calculated as follows: Ownand cross price elasticities

- Price and cross price elasticity and take a matrix $(\mathrm{m} \times \mathrm{m})$

$$
\varepsilon_{\text {Own }, \text { Cross }}=-\delta_{i j}+\left(\gamma_{i j} / W_{i}\right)-\beta_{i}\left(W_{j} / W_{i}\right) \text {. }
$$


- Intrinsic price elasticity (matrix diameter) $\left(\delta_{i j}=1\right.$, where $i=j$ ).

- Cross elasticity (outside diameter) $\left(y_{i j}=0\right.$, where $i \neq j$ ).

- Spending elasticity $y_{\text {expend }}=1+\left(y_{i} / W_{i}\right)$.

To verify the validity of the results, the relationship between the weighted spending elasticities and the commodity's share of spending is measured as follows:

$$
\Sigma_{i} W_{i} y_{\text {expend }}=1
$$

The autocorrelation was revealed using the "Breusch Godfrey" test, the problem of heterogeneity of the error term using the Engel test, and the detection of the problem of the non-normal distribution of the error term using the Jarque-Beratest. (12) I use Zellner's method to estimate simultaneous equations using Seemingly Unrelated Regression (SUR).

Second: The almost ideal demand model for citrus demand in Saudi Arabia

This section aims to estimate the demand functions of citrus fruits in Saudi Arabia using the Almost Ideal Demand System (AIDS) model, which is one of the important models used in the analysis of demand conditions of the demand function which are (addition, symmetry and homogeneity). The almost ideal demand model is derived from the expenditure function, which reflects consumer behavior in the differentiation between numbers of commodities.

The optimal demand model differs from the traditional model for estimating demand in that it takes into account the differences in the sources of commodities, it also includes special restrictions on the demand functions related to the sources of commodities, explains changes in demand, and shows the extent of competition between different sources. It provides an estimate of the degree of response of demand to prices and expenditures on food commodities required by economic policy. The model depends on the value of expenditures on the commodity, that is, its share of the total expenditure on the commodity rather than the quantity of each commodity separately. This model is efficient and easy to use, and it is more applied in economic studies.

1) The results of the statistical analysis of the Almost Ideal Demand model for Saudi citrus fruits

The results in Table 1 show the significance of the model used at the level of significance 0.05 , and it found that there is a direct relationship between orange prices and spending on orange and lemons. This shows that an increase in the price of orange by one Riyal per kilo leads to an increase in spending on oranges by 0.04 Riyals, and that the increase in the price of orange by one Riyal per kilo leads to an increase in spending on lemons by 0.02 Riyals, assuming that all other factors remain constant. It found that there is an inverse relationship between the price of each of the orange and the expenditure on tangerine. Therefore, an increase in the price of a kilo of orange by one Riyal leads to a decrease in spending on tangerine by about 0.05 Riyals, assuming the rest of the other factors remain constant. 
Table 1. Results of the semi-optimal demand model for citrus during the period (2001-2020).

\begin{tabular}{|c|c|c|c|c|c|c|c|c|c|}
\hline \multirow{2}{*}{ Commodity } & \multicolumn{3}{|c|}{ Oranges } & \multicolumn{3}{|c|}{ Lemons } & \multicolumn{3}{|c|}{ Tangerines } \\
\hline & Coeffi. & t-stat. & Prob. & Coeffi. & t-stat. & Prob. & Coeffi. & t-stat. & Prob. \\
\hline A & -2.24 & -3.96 & 0.001 & 1.34 & 3.90 & 0.001 & 1.91 & 4.76 & 0.000 \\
\hline $\operatorname{LnP} 1$ & 0.04 & 0.18 & 0.861 & 0.02 & 0.12 & 0.909 & -0.05 & -0.35 & 0.730 \\
\hline LnP2 & -0.43 & -3.33 & 0.005 & 0.22 & 2.87 & 0.012 & 0.21 & 2.26 & 0.039 \\
\hline LnP3 & 0.85 & 2.29 & 0.037 & -0.44 & -1.95 & 0.070 & -0.42 & -1.58 & 0.136 \\
\hline Ln (E/Pspi) & 0.33 & 6.09 & 0.000 & -0.12 & -3.59 & 0.003 & -0.21 & -5.55 & 0.000 \\
\hline Adj. RSq. & \multicolumn{3}{|c|}{0.81} & \multicolumn{3}{|c|}{0.49} & \multicolumn{3}{|c|}{0.82} \\
\hline Breusch-Godfrey Serial Correlation LM Test: & 0.444 & & 0.650 & 1.031 & & 0.382 & 1.308 & & 0.302 \\
\hline Heteroskedasticity Test: ARCH & 0.269 & & 0.612 & 0.957 & & 0.345 & 0.143 & & 0.711 \\
\hline Normality test: Jarque-Bera & 10.924 & & 0.404 & 0.230 & & 0.891 & 17.763 & & 0.370 \\
\hline
\end{tabular}

Adj. R-Sq.-Serial Correlation test. -Heteroskedasticity test. --Normality test. Source: gathered and calculated from: 1) Prices data sources: General Authority for Statistics (Saudi Statistics Authority). 2) Tangerines data source: FAO, the unit of measurement is tons and it has been converted to a thousand tons. 3) Amounts of oranges and lemons are from (indexmundi.com) the unit of measure is thousand tons.

The results in Table 1 show the significance of the model used at the level of significance 0.05 , and it was found that there is a direct relationship between lemon prices and spending on lemons and tangerine. This shows that an increase in the price of lemons by one Riyal per kilo leads to an increase in spending on lemons and tangerine by about 0.22 and 0.21 Riyals, respectively, assuming that other factors remain constant. It found that there is an inverse relationship between the price of lemons and spending on oranges. Therefore, an increase in the price of a kilo of lemons by one Riyal leads to a decrease in spending on orange by about 0.43 Riyals, assuming that other factors remain constant.

The results contained in Table 1 show the significance of the model used at the level of significance 0.05 , and it found that there is a direct relationship between the prices of tangerine and expenditure on orange. This shows that an increase in the price of tangerine by one Riyal per kilo leads to an increase in spending on oranges by about 0.85 Riyals, assuming that all other factors remain constant. It was also found that there was an inverse relationship between the price of each of the tangerine and the expenditure on lemons and tangerine. Therefore, an increase in the price of a kilo of tangerine by one Riyal leads to a decrease in spending on lemon and tangerine by about 0.44 and 0.42 Riyals, assuming the rest of the other factors remain constant.

The adjusted coefficient of determination reached $0.81,0.49,0.82$, meaning that about $81 \%, 49 \%, 82 \%$ of the changes in the shares of oranges, lemons and tangerines, respectively, are due to changes in the independent factors studied and the rest to other factors that not taken into consideration.

It is clear from the results of Table 1 that the Birchall's test for serial correlation, the heteroskedasticity test, and the test of the normality are not significant. 
Therefore, that the data follow the normal distribution of the model and there is no problem of heteroskedasticity.

2) Matrix of price, cross, and expenditure Elasticities of the almost ideal demand model for Saudi Citrus

Table 2 indicates that a change in orange prices by $1 \%$ leads to a decrease in demand for oranges by 1.25 . As for lemon, a $1 \%$ change in the price of lemon leads to an increase in demand for lemon by 0.12 . As for the tangerines, the change in the price of tangerines by $1 \%$ leads to a decrease in the demand for tangerines by 3.21 .

The cross-price elasticity indicates that a change in the price of orange by $1 \%$ leads to a decrease in the demand for orange by 1.25 . While the change in the price of orange by $1 \%$ leads to an increase in the demand for lemons by 0.28 . While the change in the price of orange by $1 \%$ leads to an increase in the demand for tangerine by 0.32 as it is clear that there is an integrative relationship between oranges and lemons, and there is also an integrative relationship between orange and tangerine.

The cross price elasticity indicates that a change in the price of lemon by $1 \%$ leads to a decrease in the demand for orange by 1.00 . While the change in the price of lemon by $1 \%$ leads to a decrease in the demand for lemon by 0.12 . While the change in the price of lemons by $1 \%$ leads to an increase in the demand for tangerine by 1.53 as it is clear that there is a substitution relationship between lemons and oranges and the existence of an integrative relationship also between lemons and tangerines.

The cross-price elasticity indicates that a change in the price of tangerine by $1 \%$ leads to an increase in the demand for orange by 1.55 . While the change in the price of tangerine by $1 \%$ leads to decrease in the demand for lemons by 1.54 . While the change in the price of tangerine by $1 \%$ leads to a decrease in the demand for tangerine by 3.21 , as it is clear that there is a complementary relationship between tangerine and orange and the existence of a substitutional relationship between tangerine and lemons.

The expenditure elasticity on oranges indicates that a change in the total consumption expenditure on orange by $1 \%$ leads to an increase in spending on orange by $1.63 \%$. It is clear from this that positive sign indicating that they are

Table 2. The matrix of price, junction and spending elasticities of the semi-optimal demand model for citrus.

\begin{tabular}{ccccc}
\hline \multirow{2}{*}{ Elasticity } & \multicolumn{2}{c}{ elasticity of price and intersection } & Spending \\
\cline { 2 - 4 } Commodity & oranges & lemons & Tangerines & \\
\hline Oranges & -1.25 & -1.00 & 1.55 & 1.63 \\
Lemons & 0.28 & -0.12 & -1.54 & 0.57 \\
Tangerines & 0.32 & 1.53 & -3.21 & -0.22 \\
\hline
\end{tabular}

Source: Table 1 in the research. 
ordinary commodities. The spending elasticity on lemons indicates that a change in total consumption expenditure on lemons by $1 \%$ leads to an increase in spending on lemons by 0.57 . It is clear from the tangerine negative sign expenditure elasticity that tangerine is inferior fruit.

\section{Recommendations}

Based on the results of the study, which reached several recommendations are viewed as follow:

1) Due to the lack of studies nowadays, the necessity, and the need for them in light of the circumstances of the Corona virus, this calls for a recommendation to increase studies in this regard due to its importance.

2) From estimating the price elasticities of the three commodities, it is concluded that the demand for lemons is inelastic, while the demand for both oranges and tangerines were more elastic, which calls for the need to direct and concentrate policy makers to maintain an appropriate price that is accessible to all categories of consumers in Saudi Arabia, and for the lemons due to its importance and versatility in various types of food such as juices, etc., in addition to the lack of alternatives to it in most of its uses. In contrast to the orange and tangerine commodities, the demand for them was more elastic and the possibility of replacing them together was greater.

3) From the estimation of expenditure elasticities, it found that both lemons and orange are normal commodities for the consumer, while it was found that the tangerine commodity is considered an inferior commodity.

4) From estimating the cross-price elasticities and obtaining the negative sign for them, it indicated that both (lemon and orange) and (lemon and tangerine) are considered non-substitute commodities to each other. The positive sign indicated that both (oranges and tangerines) are considered substitute commodities to each other. Thus, the study recommends the need to take advantage of these relationships for researchers and policy makers in determining production and import priorities according to the importance of these commodities and the possibility of replacing them or not.

\section{Conclusion}

The research examined the application of this model in the study of domestic demand for the most important commodities consumed in Saudi Arabia (orange-lemon-tangerines). The results show that the suggested model obtained conditions of the application function, which are addition, homogeneity, symmetry, price, cross demand and expenditure elasticities.

The study found that there is a direct relationship between orange prices and spending on orange and lemons. This shows that an increase in the price of orange by one Riyal per kilo leads to an increase in spending on oranges by 0.04 Riyals, and that the increase in the price of orange by one Riyal per kilo leads to an increase in spending on lemons by 0.02 Riyals. Assuming that all other factors 
remain constant, it found that there is an inverse relationship between the price of each of the orange and the expenditure on tangerine. Therefore, an increase in the price of a kilo of orange by one Riyal leads to a decrease in spending on tangerine by about 0.05 Riyals, assuming the rest of the other factors remain constant.

And that there is a direct relationship between the prices of tangerine and expenditure on orange. This shows that an increase in the price of tangerine by one Riyal per kilo leads to an increase in spending on oranges by about 0.85 Riyals, assuming that all other factors remain constant. It was also found that there was an inverse relationship between the price of each of the tangerine and the expenditure on lemons and tangerine. Therefore, an increase in the price of a kilo of tangerine by one Riyal leads to a decrease in spending on lemon and tangerine by about 0.44 and 0.42 Riyals, assuming the rest of the other factors remain constant.

The adjusted coefficient of determination reached $0.81,0.49,0.82$, meaning that about $81 \%, 49 \%, 82 \%$ of the changes in the shares of oranges, lemons and tangerines, respectively, are due to changes in the independent factors studied and the rest to other factors that not taken into consideration.

That the Birchall's test for serial correlation, the heteroskedasticity test and the test of the normality are not significant. Therefore, the data follow the normal distribution of the model and there is no problem of heteroskedasticity.

Thus, the study recommends the need to take advantage of these relationships for researchers and policy makers in determining production and import priorities.

\section{Acknowledgements}

The authors would like to thank the Deanship of Scientific Research at King Faisal University for funding this study.

\section{Conflicts of Interest}

The authors declare no conflicts of interest regarding the publication of this paper.

\section{References}

Al-Duwais, A. M., Alderiny, M. M., kotb, A. A., Ahamed, S. E. B., \& Alropy, E. T. (2019). Application of Mathematical Model to the Almost Ideal Demand System for the Fruit Imports in the Kingdom of Saudi Arabia. Journal of Experimental Biology and Agricultural Sciences, 7, 387-395. https://doi.org/10.18006/2019.7(4).387.395 https://www.cabdirect.org/cabdirect/abstract/20203480764

Al-Mahish, M., Abd EL-Radyhanady, M. Hafsa (2021). Fish Demand in Egypt: An Analysis Using Almost Ideal Demand System (AIDS). Indian Journal of Fisheries, 68. https://scholar.google.com/citations?view op=view citation\&hl=ar\&user=Rx7ElLQAA AAJ\&citation for view=Rx7EILQAAAAJ:M3ejUd6NZC8C https://doi.org/10.21077/ijf.2021.68.3.90651-20 
Amin, Q. I. F., \& Ali Mohamed, A.-F. I. (2020). Estimation of the Semi-Optimal Demand Model for Egyptian Orange Exports in the Most Important Foreign Markets. Journal of Agricultural Economics and Social Sciences, 5, 281-290.

https://jaess.journals.ekb.eg/article 100762.html

Mohamad, A., \& Mahmoud, A. (2019). Analysis of Saudi Demand for Imported Honey Using an Almost Ideal Demand System (AIDS). Journal of the Saudi Society of Agricultural Sciences, 19, 293-298. https://doi.org/10.1016/j.jssas.2019.05.001 https://www.sciencedirect.com/science/article/pii/S1658077X19300669

Sahinli, M. A., \& Fidan, H. (2012). Estimation of Food Demand in Turkey: Method of an Almost Ideal Demand System. Quality \& Quantity, 46, 653-663.

https://idp.springer.com/authorize/casa?redirect uri=https://link.springer.com/article/ 10.1007/s11135-010-9419-4\&casa token=nQoH2eED1AMAAAAA:NTKFuBkRspXtqZ i6NNb6RSmOYNLdLEwUjpXFIwaN2LFv8n0AsTrU9adGDKSA6VpJx6Qr5kWM5u1C jzhChg

Torres, M. J. M. (1996). Almost Ideal Demand System: Citrus Fruit Demand Elasticities in Germany. Acta Horticulturae, 429, 445-452.

https://doi.org/10.17660/ActaHortic.1996.429.56

https://www.actahort.org/books/429/429 56.htm 
A. A. Kinawy et al.

\section{Appendixes}

Table A1. Prices and consumption of the most important citrus fruits in the Kingdom of Saudi Arabia during the period 2001-2020.

\begin{tabular}{|c|c|c|c|c|c|c|}
\hline \multirow[b]{2}{*}{ year } & \multicolumn{2}{|c|}{ Orange } & \multicolumn{2}{|c|}{ Limon } & \multicolumn{2}{|c|}{ Tangerine } \\
\hline & $\begin{array}{l}\text { Consumption } \\
\text { (1000 tons) }\end{array}$ & $\begin{array}{c}\text { Prices } \\
\text { (Riyal per kilo) }\end{array}$ & $\begin{array}{l}\text { Consumption } \\
\text { (1000 tons) }\end{array}$ & $\begin{array}{c}\text { Prices } \\
\text { (Riyal per kilo) }\end{array}$ & $\begin{array}{l}\text { Consumption } \\
\text { (1000 tons) }\end{array}$ & $\begin{array}{c}\text { Prices } \\
\text { (Riyal per kilo) }\end{array}$ \\
\hline $2001^{\star}$ & 85 & 3.97 & 45 & 5.43 & 42 & 6.58 \\
\hline $2002^{*}$ & 71 & 3.85 & 63 & 4.91 & 61 & 5.87 \\
\hline $2003^{\star}$ & 60 & 3.81 & 56 & 4.72 & 46 & 5.83 \\
\hline $2004^{\star}$ & 56 & 3.82 & 62 & 4.74 & 48 & 5.72 \\
\hline $2005^{\star}$ & 142 & 3.87 & 85 & 4.79 & 56 & 5.77 \\
\hline $2006^{*}$ & 270 & 3.88 & 79 & 4.86 & 53 & 5.84 \\
\hline $2007^{\star}$ & 280 & 4.3 & 60 & 5.34 & 35 & 6.43 \\
\hline $2008^{*}$ & 270 & 5 & 100 & 7.78 & 52 & 6.94 \\
\hline $2009^{*}$ & 302 & 4.76 & 103 & 5.79 & 20 & 6.36 \\
\hline $2010^{\star}$ & 312 & 5.22 & 104 & 6.36 & 57 & 6.38 \\
\hline $2011^{\star}$ & 348 & 5.14 & 85 & 6.29 & 58 & 6.41 \\
\hline $2012^{\star}$ & 274 & 4.77 & 88 & 6.97 & 58 & 6.17 \\
\hline $2013^{*}$ & 274 & 5.08 & 85 & 8.01 & 71 & 6.56 \\
\hline $2014^{*}$ & 404 & 4.99 & 103 & 8.42 & 73 & 6.3 \\
\hline $2015^{\star}$ & 392 & 4.99 & 102 & 8.12 & 63 & 6.4 \\
\hline $2016^{*}$ & 374 & 4.97 & 123 & 8.23 & 86 & 6.71 \\
\hline $2017^{\star}$ & 380 & 5 & 125 & 7.51 & 71 & 6.3 \\
\hline $2018^{\star}$ & 402 & 4.89 & 124 & 7.55 & 84 & 6.63 \\
\hline $2019^{*}$ & 387 & 4.84 & 126 & 7.19 & 77 & 6.24 \\
\hline $2020^{\star}$ & 395 & 6.3 & 128 & 7.95 & 79 & 6.83 \\
\hline Average & 273.9 & 4.67 & 92.3 & 6.55 & 59.5 & 6.31 \\
\hline
\end{tabular}

Source: General Authority for Statistics (Saudi Statistics Authority), Tangerines data source: FAO, the unit of measurement is tons and it has been converted to a thousand tons, Amounts of oranges and lemons are from (indexmundi.com). 